\title{
PROGRAM PENDAMPINGAN KEWIRAUSAHAAN BAGI UKM DAY TEA INDONESIA, CIWIDEY, KABUPATEN BANDUNG
}

\author{
Hetty Karunia Tunjungsari ${ }^{1}$, Mei $\mathrm{Ie}^{2}$ dan Chairy Chairy $^{3}$ \\ ${ }^{1}$ Jurusan Manajemen, Universitas Tarumanagara Jakarta \\ Email: hetty@fe.untar.ac.id \\ ${ }^{1}$ Jurusan Manajemen, Universitas Tarumanagara Jakarta \\ Email: meii@fe.untar.ac.id \\ 2 Jurusan Manajemen Bisnis, Universitas Presiden, Cikarang \\ Email: chairy@president.ac.id
}

\begin{abstract}
In 2020, the world is experiencing a global crisis due to the COVID-19 pandemic that has hit a large number of countries in the world. The economic crisis triggered by the health crisis has even created various problems for SMEs in Indonesia, especially SMEs which have only marketed their products conventionally in the physical market. The urge to switch from the physical market to the digital market is not only due to the pandemic, but also because in this digital era consumers tend to prefer products that can be accessed in the digital market. This community engagement activity was carried out to help Day Tea Indonesia, an SME located in Ciwidey, Bandung Regency. Currently, products produced by this SME is sold in gift shops that are usually visited by tourists in Ciwidey, but due to the reduced number of tourists since the COVID-19 pandemic, sales in physical stores have decreased dramatically. SME owners have started to market their products in digital markets such as in Tokopedia or using Facebook. However, the marketing is felt to be ineffective. The survey conducted by the community engagement team concluded that one of the obstacles that resulted in the lack of product attractiveness was due to poor quality of packaging. Although Day Tea Indonesia products are considered as premium quality tea, because consumers get the first impression of product quality through the appearance of the packaging, the existing packaging is still inadequate. The community engagement team provides entrepreneurship assistance by developing packaging designs for Day Tea Indonesia as an effort to increase product attractiveness for consumers.
\end{abstract}

Keywords: entrepreneurship assistance, packaging, SME, marketing, culinary

\begin{abstract}
ABSTRAK
Di tahun 2020 ini dunia mengalami krisis global sebagai dampak pandemi COVID-19 yang melanda sejumlah besar negara di dunia. Krisis ekonomi yang dipicu oleh krisis kesehatan ini bahkan memunculkan berbagai masalah bagi pelaku UKM di Indonesia, terutama UKM yang selama ini hanya memasarkan produk secara konvensional di pasar fisik. Dorongan untuk beralih dari pasar fisik ke pasar digital tidak hanya terjadi karena adanya pandemi, namun juga karena di era digital ini konsumen cenderung lebih menyukai produk-produk yang dapat diakses di pasar digital. Kegiatan PKM ini dilakukan untuk membantu UKM Day Tea Indonesia yang terletak di Ciwidey, Kabupaten Bandung. Selama ini produk yang dihasilkan oleh UKM dijual di toko oleh-oleh yang biasa dikunjungi oleh wisatawan di Ciwidey, namun karena berkurangnya jumlah wisatawan sejak terjadinya pandemi COVID-19, penjualan di toko fisik menurun drastis. Pemilik UKM sudah mulai mencoba memasarkan produknya di pasar digital seperti di Tokopedia maupun menggunakan media sosial Facebook. Namun demikian pemasarannya dirasakan tidak efektif. Survey yang dilakukan oleh tim PKM menghasilkan kesimpulan bahwa salah satu kendala yang mengakibatkan kurangnya daya tarik produk adalah karena kemasan yang kurang berkualitas. Meskipun produk Day Tea Indonesia merupakan produk teh berkualitas premium, karena konsumen mendapatkan kesan pertama akan kualitas produk melalui tampilan kemasan, maka kemasan yang digunakan saat ini masih kurang memadai. Tim PKM melakukan pendampingan kewirausahaan dengan mengembangkan desain kemasan bagi Day Tea Indonesia sebagai upaya untuk meningkatkan daya tarik produk bagi konsumen.
\end{abstract}

Kata kunci: pendampingan kewirausahaan, kemasan, UKM, pemasaran, kuliner

\section{PENDAHULUAN}

Sebagaimana kita ketahui bersama, sejak akhir tahun 2019 yang lalu dunia tengah mengalami krisis kesehatan yang kemudian bersambung dengan krisis ekonomi global. Sektor ekonomi di berbagai negara mengalami kemerosotan karena terhentinya produksi, bahkan tidak sedikit perusahaan-perusahaan skala kecil hingga besar terpaksa menutup usahanya karena tidak mampu lagi membiayai kegiatan operasional bisnisnya. 
Belajar dari krisis ekonomi di tahun 1998 dan tahun 2008, UKM merupakan pelaku bisnis yang cukup tangguh dan mampu mempertahankan bisnisnya pada kala itu. Hal ini ditengarai karena UKM pada dasarnya memiliki kemampuan untuk tetap beroperasi dalam skala minimal dan tidak banyak dipengaruhi oleh tingkat inflasi yang diakibatkan oleh kenaikan nilai tukar mata uang asing yang menjadi penyebab krisis di masa itu.

Namun demikian, krisis yang terjadi di tahun 2020 ini sepertinya memiliki karakteristik yang berbeda dengan krisis-krisis sebelumnya. Penurunan aktivitas ekonomi bukan diakibatkan oleh kenaikan nilai tukar mata uang asing, tetapi didominasi oleh kebijakan global untuk menghentikan kegiatan produksi di berbagai sektor yang kemudian berdampak pada hilangnya pendapatan bisnis secara luas. Karena tidak dapat beroperasi, perusahaan-perusahaan kemudian harus melakukan pembatasan jam kerja, penundaan kegiatan, hingga PHK massal. Banyaknya masyarakat yang berasal dari karyawan terdampak pada akhirnya mengakibatkan penurunan daya beli secara luas.

Di Indonesia, sektor kuliner menjadi salah satu sektor industri yang mengalami dampak peraturan pemerintah dalam upaya penanganan COVID-19. Industri yang bergerak di bidang restoran pada periode tertentu terpaksa harus ditutup untuk menghindari keramaian. Saat mulai diperbolehkan untuk beroperasi kembali, aturan pemerintah menetapkan kapasitas yang diperbolehkan hanya maksimal $50 \%$ dari kapasitas restoran. Hal ini tentu menimbulkan permasalahan baru, restoran yang biasanya mampu menghasilkan pendapatan penuh dari pengunjung kemudian mengalami penurunan pendapatan karena berkurangnya pengunjung.

Untuk mengatasi masalah pembatasan kegiatan operasional, sejumlah restoran kemudian menawarkan layanan pesan antar hingga menjual produk frozen agar pelanggan tetap dapat menikmati makanan yang biasa mereka beli di restoran. Memang sensasi menikmati makanan di restoran dengan menikmati makanan di rumah tentu berbeda, namun layanan ini banyak diminati oleh pelanggan untuk dapat menjaga kesehatan dan juga tetap menikmati makanan dari restoran favorit mereka.

Masih di sektor kuliner, jenis usaha yang mengalami dampak signifikan dari adanya pandemi ini adalah UKM oleh-oleh yang biasa terletak di daerah wisata. Sejak adanya pandemi COVID-19, UKM oleh-oleh yang biasanya ramai dikunjungi oleh wisatawan yang ingin membeli oleh-oleh di daerah wisata mengalami penurunan pendapatan yang signifikan. Hal ini dikarenakan adanya kebijakan pemerintah untuk menutup obyek wisata sehingga tidak ada lagi wisatawan yang berkunjung selama masa pandemi belum berakhir. Karena pembeli utama UKM oleh-oleh adalah wisatawan, tentu jumlah pembeli berkurang drastis.

Sebagai salah satu usaha di sektor yang terkena imbas, UKM oleh-oleh yang terletak di daerah wisata membutuhkan banyak penyesuaian pengelolaan usaha agar bisa tetap bertahan dan bahkan berkembang dalam jangka panjang. Salah stau cara yang dapat dilakukan adalah menawarkan produknya di pasar digital seperti Tokopedia, Bukalapak, Shopee, dan lain-lain. Target konsumen bisa berasal dari pelanggan yang sebelumnya telah mengenal produk saat berkunjung ke daerah wisata, atau bahkan konsumen baru yang memiliki minat akan produk yang dihasilkan UKM.

Mitra kegiatan PKM ini adalah UKM Day Tea Indonesia yang terletak di Ciwidey, Kabupaten Bandung. Sebelum terjadi pandemi, omset penjualan produk teh yang dihasilkan oleh UKM ini rata-rata adalah Rp500 ribu per hari dan bahkan di masa liburan bisa mencapai Rp25 juta per bulan. Namun sejak terjadi pandemi, toko hanya menjual 1-2 produk per hari bahkan sering tidak ada penjualan sama sekali. Meskipun di bulan April 2020 Bapak Dedi selaku pemilik telah mencoba memasarkan produknya di Tokopedia dan berbagai grup Whatsapp, namun hingga awal November 
saat tim melakukan survey ke lokasi, penjualan yang dihasilkan dari pasar digital ini masih belum optimal.

UKM Day Tea Indonesia didirikan oleh Bapak Dedi di tahun 2018. Lokasi Day Tea Indonesia terletak di Jalan Jl. Raya Ciwidey No. 52 Desa Pasir Jambu Kecamatan Pasir Jambu, Kabupaten Bandung. Outlet Day Tea Indonesia selain menyediakan produk oleh-oleh berupa teh produksi petani Ciwidey juga memiliki restoran yang menyediakan seduhan teh dan kopi serta makanan lain. Namun demikian, produk utama Day Tea Indonesia adalah teh dalam kemasan. Beberapa foto terkait dengan UMKM ini dapat dilihat pada Gambar 1,2 dan 3.

\section{Gambar 1}

Situasi Etalase Toko Day Tea Indonesia

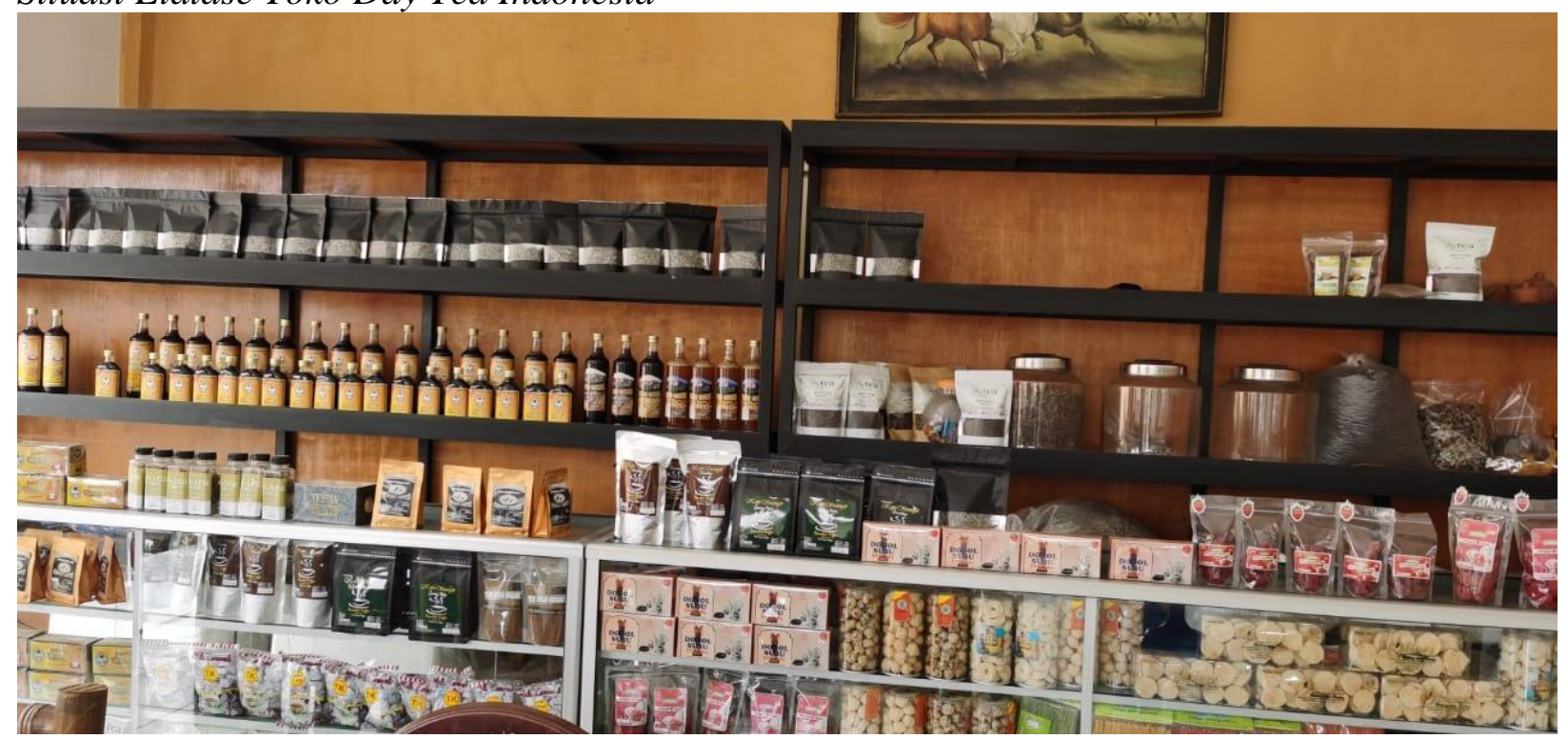

\section{Gambar 2}

Produk Day Tea Indonesia

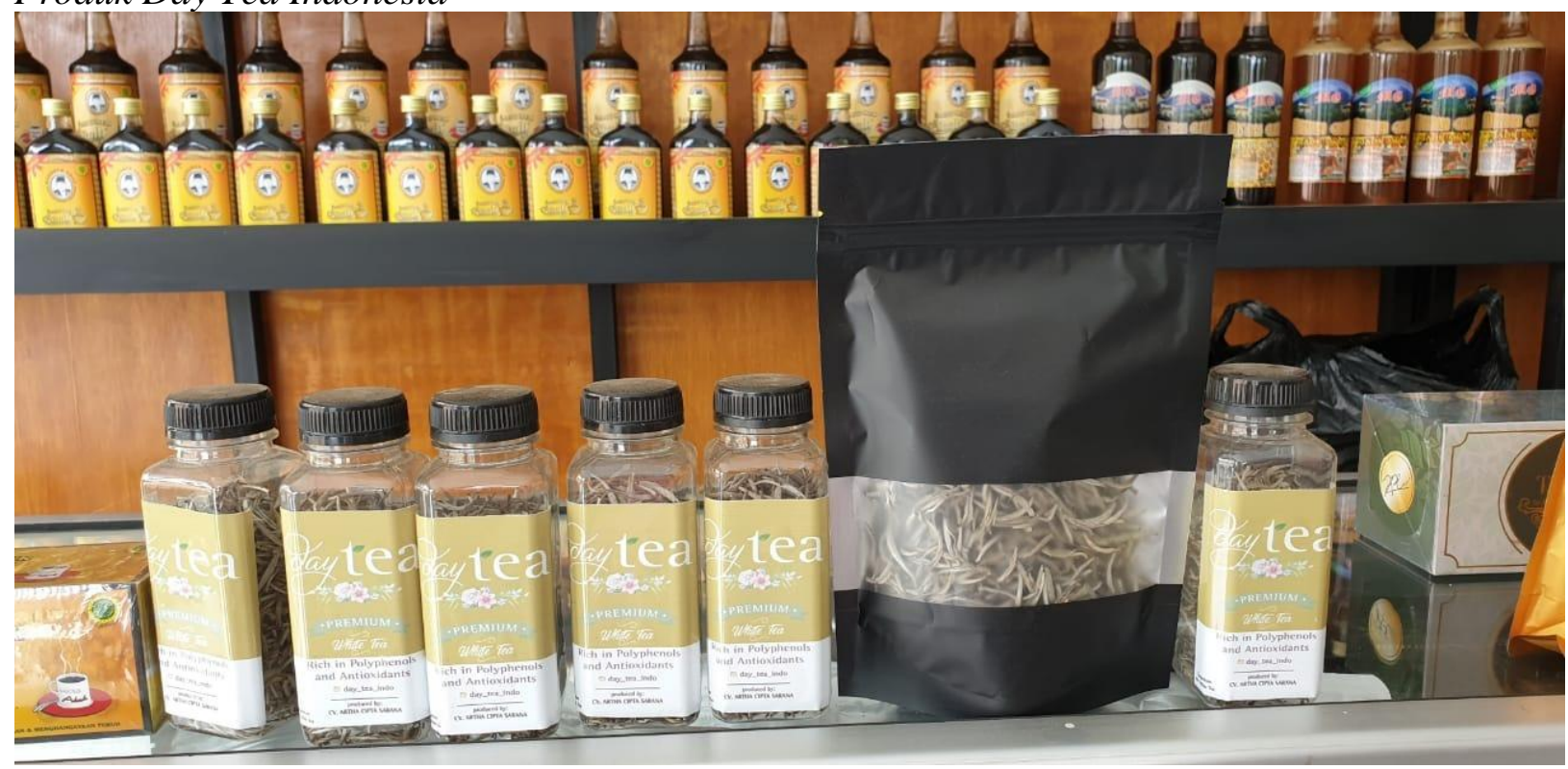




\section{Gambar 3}

\section{Survey Mitra PKM dan Penandatanganan Surat Mitra}

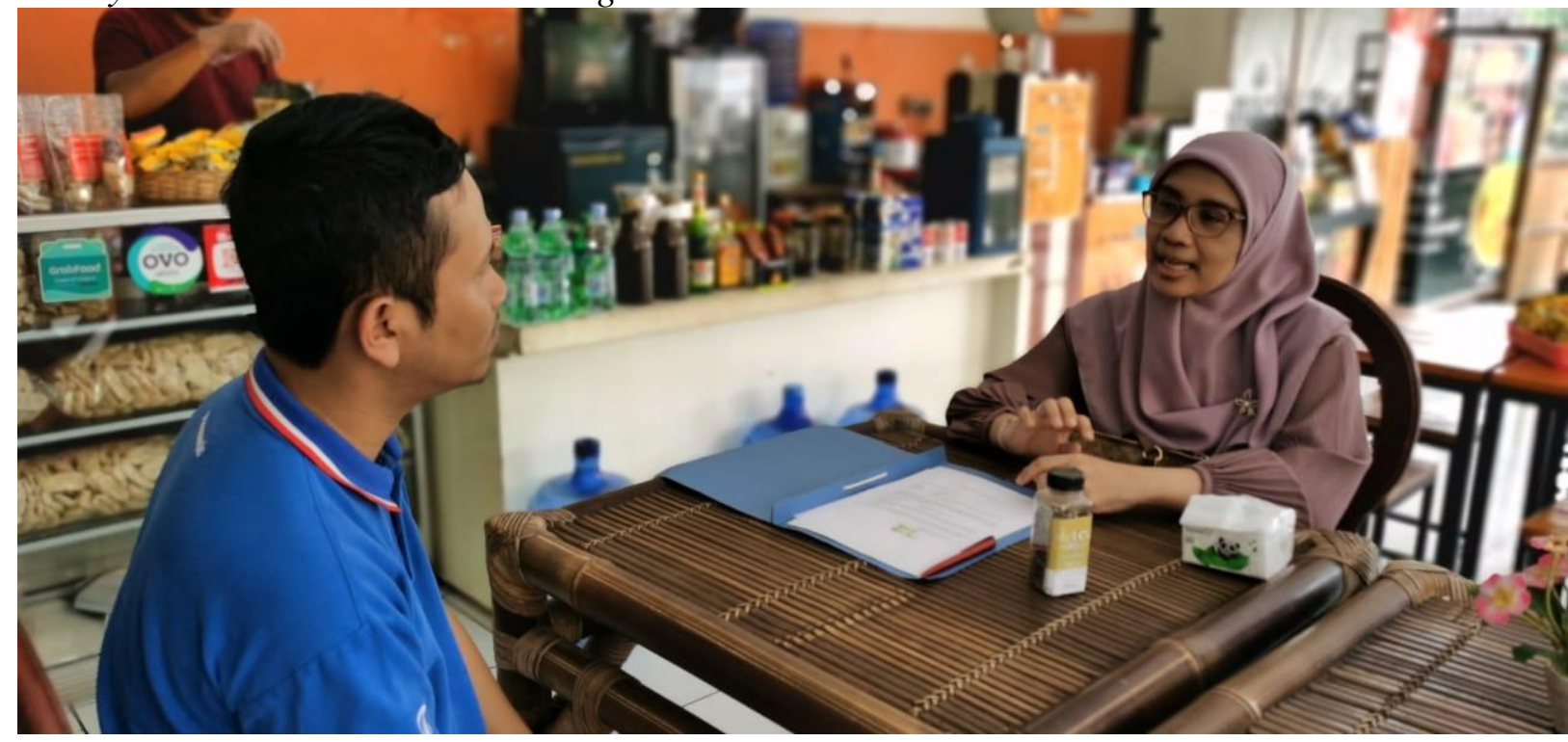

Saat memasarkan produk secara fisik di outlet, UKM Day Tea Indonesia relatif tidak mengalami masalah dengan minat pembeli karena pembeli dapat melihat secara langsung kualitas produk yang dijual di toko. Selain itu, pengunjung yang mencicipi seduhan teh di restoran Day Tea Indonesia, mayoritas kemudian tertarik untuk membeli teh yang telah dikemas sebagai oleh-oleh atau untuk dikonsumsi sendiri saat kembali ke daerah masing-masing.

Kondisi penjualan di pasar fisik berbeda dengan penjualan bagi konsumen di pasar digital. Karena tidak dapat mengamati produk secara langsung, calon pembeli di pasar digital yang belum pernah mengenal produk sebelumnya akan melakukan pembelian berdasarkan kelengkapan informasi yang dia peroleh. Informasi yang dikumpulkan oleh konsumen untuk melakukan pengambilan keputusan meliputi spesifikasi produk, reputasi produk maupun produsen, hingga persepsi atas kualitas produk yang diperoleh melalui tampilan produk di pasar digital.

Berdasarkan diskusi dengan bapak Deni selaku pemilik Day Tea Indonesia, diperlukan peningkatan kualitas produk agar lebih dapat memiliki daya tarik di pasar digital. Untuk bisa memasarkan produknya secara efektif di pasar digital, penyesuaian yang dilakukan oleh UKM tidak hanya sekedar menyediakan akses konsumen ke pasar digital, tetapi juga meliputi kegiatan yang lebih luas seperti misalnya penyesuaian desain produk, desain kemasan, proses produksi, hingga proses distribusi produk. Salah satu cara yang dibutuhkan untuk meningkatkan daya tarik produk adalah dengan menampilkan kemasan yang tepat. Menurut Kotler \& Keller (2012) pengemasan adalah seluruh aktivitas mendesain dan memproduksi tempat untuk sebuah produk. Pengemasan harus mencapai sejumlah sasaran yaitu: 1) mengidentifikasi merek, 2) menyampaikan informasi yang deskriptif dan persuasif, 3) memfasilitasi transportasi dan proteksi produk, 4) membantu penyimpanan di rumah, dan 5) membantu konsumsi produk.

Kemasan produk akan mempengaruhi psikologi konsumen agar membeli produk (LIPI, n.d.). Penggiat UMKM harus menyadari pentingnya desain kemasan produknya. UMKM harus mengikuti tren pasar, bahkan kalau bisa menciptakan tren sehingga produknya laku di pasaran. Berdasarkan analisis di atas, dapat disimpulkan bahwa permasalahan mitra adalah pada bidang produksi dan manajemen. 


\section{METODE PELAKSANAAN PKM}

Metode pelaksanaan yang akan digunakan dalam kegiatan ini adalah sebagai berikut:

1. Pengumpulan data dan penyusunan proposal

Dalam menyusun proposal kegiatan PKM, tim melakukan wawancara dengan pemilik dan pendiri UKM Day Tea Indonesia untuk mengidentifikasi masalah mitra. Setelah diketahui permasalahan yang dihadapi mitra, tim PKM melakukan studi literatur untuk mencari solusi yang tepat bagi permasalahan mitra.

2. Pelaksanaan

Pelaksanaan kegiatan PKM adalah dengan melakukan konsultasi secara online dengan menggunakan media Zoom meeting dan diskusi di pesan WA.

3. Penyusunan dan penyerahan laporan

Kegiatan ini dilaksanakan untuk Day Tea Indonesia. Tujuan kegiatan PKM adalah untuk meningkatkan aktivitas pemasaran melalui pengembangan kemasan. Setelah kegiatan ini dilaksanakan maka tim PKM akan menyusun laporan dan menyusun draft publikasi terkait dengan kegiatan ini. Hasil dari kegiatan ini nantinya akan dijadikan dasar untuk menyusun rencana kegiatan lanjutan.

Tahapan solusi bidang manajemen dan bidang produksi dijelaskan pada Gambar 4 dan Gambar 5.

\section{Gambar 4}

Tahapan Solusi Bidang Manajemen

Survey mitra
Mentoring

\section{Gambar 5}

Tahapan Solusi Bidang Produksi

\begin{tabular}{|c|c|c|}
\hline Persiapan & Pelaksanaan & Pelaporan \\
\hline -Survey mitra & -Mentoring & -Penyusunan laporan \\
\hline $\begin{array}{l}\text {-Analisis kebutuhan } \\
\text { mitra }\end{array}$ & $\begin{array}{l}\text {-Pembuatan desain } \\
\text { kemasan }\end{array}$ & $\begin{array}{l}\text { •penyusunan artikel } \\
\text { publikasi }\end{array}$ \\
\hline
\end{tabular}

Dalam kegiatan PKM ini pemilik UKM Day Tea Indonesia sebagai mitra akan berperan sebagai narasumber yang memberikan informasi terkait produk dan kapabilitas manajemen yang telah dijalankan selama ini. Bapak Dedi akan memberikan informasi yang dibutuhkan oleh tim PKM untuk dapat menyusun strategi pemasaran online serta desain kemasan yang tepat untuk Day Tea Indonesia.

\section{HASIL DAN PEMBAHASAN}

Kegiatan PKM ini bertujuan untuk membantu mitra menyelesaikan permasalahan manajemen dan produksi. Permasalahan yang dihadapi oleh mitra ini terutama dirasakan saat masa pandemi COVID-19 memasuki Indonesia dan mengubah situasi dunia secara luas di akhir 2019 lalu. Pada 
masa sebelum pandemi, penjualan teh dari Day Tea Indonesia dapat mencapai 100kg per bulan. Namun karena pandemi memaksa dilakukannya penyesuaian kegiatan di berbagai sektor, termasuk sektor perkebunan dan hasil olahannya, kondisi ini dialami pula oleh Day Tea Indonesia. Pada pelaksanaan kegiatan PKM, tim PKM menemukan bahwa permasalahan utama yang dihadapi oleh Day Tea Indonesia adalah pada bidang pemasaran dan manajemen usaha. Berdasarkan hasil pengamatan dan diskusi intensi dengan pemilik Day Tea Indonesia, diperoleh kesimpulan bahwa solusi pada bidang pemasaran akan disiapkan kemasan dengan desain yang lebih menarik dan kekinian. Adapun solusi pada bidang manajemen terkait dengan sistem penjualan Day Tea Indonesia yang saat ini masih dijalankan secara offline perlu ditingkatkan ke pasar online.

Dalam mengembangkan desain kemasan, tim PKM melibatkan mahasiswa dan Fakultas Seni Rupa dan Desain untuk mendesain kemasan. Terdapat 3 jenis produk yang dipasarkan oleh Day Tea Indonesia: teh hitam (black tea), teh hijau (green tea), dan teh putih (white tea). Tim PKM mengembangkan 3 jenis kemasan untuk ketiga produk ini dengan tetap mempertahankan citra Day Tea Indonesia. Gambar 6 adalah kemasan yang dihasilkan pada kegiatan PKM ini yang meliputi kemasan untuk produk black tea, green tea dan white tea. Desain disusun berdasarkan diskusi dengan pemilik dan juga survey pada sejumlah pelanggan Day Tea Indonesia. Desain final merupakan desain yang telah mengakomodasi keinginan pemilik, pendapat dari pelanggan dan juga inspirasi dari tim PKM.

\section{Gambar 6}

\section{Desain Kemasan Day Tea Indonesia}
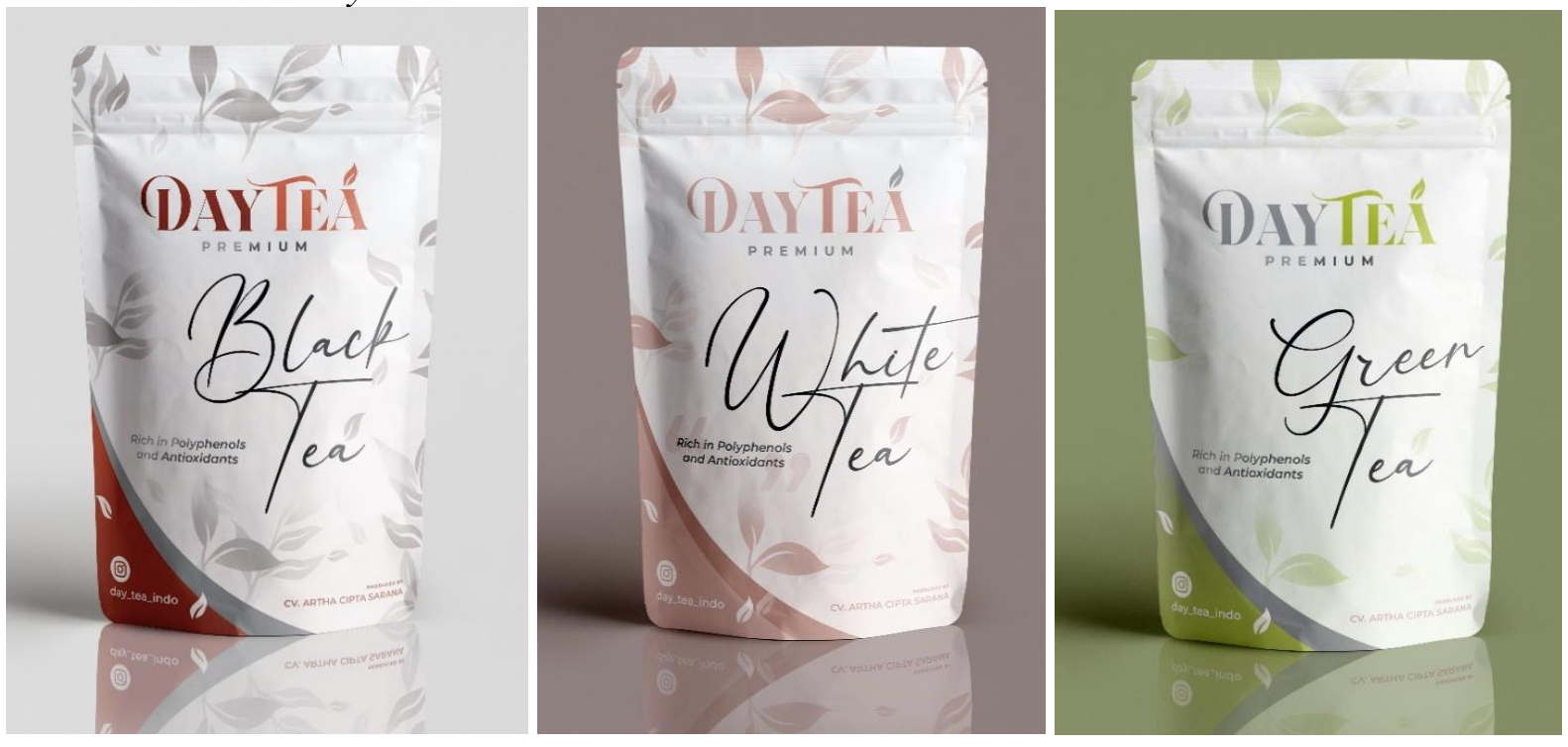

Kegiatan PKM ini merupakan salah satu bentuk kontribusi akademisi dalam meningkatkan potensi pemasaran UKM melalui pengembangan kemasan. Kemasan yang lebih menarik dapat meningkatkan minat beli konsumen, khususnya jika produk dipasarkan secara online. Salah satu kegiatan PKM serupa juga telah dilakukan oleh Selamat et al. (2021) pada UKM stik tempoyak di Jambi. Dengan menggunakan kemasan yang lebih modern, pelanggan lebih tertarik untuk membeli produk. Hal ini dialami khususnya pada pelanggan baru yang sebelumnya tidak mengenal produk UKM. Oleh sebab itu, diharapkan nantinya dapat diperoleh pelanggan-pelanggan baru jika Day Tea Indonesia telah memasarkan produknya dengan kemasan yang baru. 
Pengembangan strategi komunikasi pemasaran secara online juga dilakukan oleh tim PKM untuk membantu Day Tea Indonesia memasarkan produknya secara online. Tim PKM membantu menyusun poster digital yang dapat digunakan oleh Day Tea Indonesia untuk mengirimkan blast message melalui media sosial, seperti melalui Instagram, Facebook, atau messenger Whatsapp. Poster digital sangat penting dimiliki oleh UKM untuk dapat dengan mudah menyebarluaskan informasi mengenai produknya secara online. Metode ini telah banyak diadopsi oleh berbagai perusahaan di berbagai tingkatan usaha. Bahkan pemerintah mendorong UKM untuk segera beroperasi secara online sejak terjadinya pandemi COVID-19. Tuwohingide et al. (2018) juga melakukan kegiatan PKM k pemanfaatan media sosial untuk promosi dan pemasaran produk UKM di Kampung Bowongkulu.

Pada kegiatan selanjutnya, PKM seperti ini dapat dikembangkan dalam bentuk penyusunan website guna mendukung pemasaran online UKM. Hal ini telah dilakukan Prasetya et al. (2020) dan Selamat et al. (2020) yang membantu mengembangkan website bagi UKM dalam upaya meningkatkan potensi pemasaran secara online.

\section{KESIMPULAN DAN SARAN}

Secara umum kegiatan PKM dapat dijalankan dengan baik tanpa kendala yang signifikan, walaupun kegiatan dilaksanakan pada masa pandemi COVID-19. Pemilik Day Tea Indonesia menyatakan sangat terbantu dengan adanya kegiatan pendampingan kewirausahaan yang dilakukan oleh tim PKM, khususnya karena kegiatan ini telah menghasilkan desain kemasan yang lebih modern bagi produk mereka. Dengan adanya desain yang lebih menarik, Day Tea Indonesia diharapkan mampu memasuki pasar digital dan memiliki daya saing yang mencukupi. Selain itu, pengembangan poster promosi media sosial yang telah dilakukan dalam kegiatan PKM ini juga memberi manfaat yang berarti bagi Day Tea Indonesia. dengan adanya poster digital, pemilik UKM dapat menyebarluaskan informasi produknya melalui berbagai media sosial dengan mudah dan menarik.

Kegiatan pendampingan ini dilakukan dengan tujuan untuk membantu UKM meningkatkan potensi kewirausahaan, yakni dengan mengembangkan kemasan baru yang lebih menarik dan lebih memiliki daya saing di pasar online, serta mengembangkan poster promosi media sosial. Di masa mendatang, kegiatan PKM serupa dapat kembali dilakukan pada UKM-UKM yang membutuhkan bantuan peningkatan potensi kewirausahaan di pasar online. Selain itu, kegiatan PKM dapat pula dilakukan di Day Tea Indonesia dengan mengembangkan website yang mampu dimanfaatkan oleh UKM untuk mempromosikan produknya secara lebih luas.

\section{Ucapan Terima Kasih (Acknowledgement)}

Pada kesempatan ini tim PKM menyampaikan ucapan terima kasih pada LPPM Universitas Tarumanagara yang telah memberikan pendanaan kegiatan PKM ini melalui skema hibah PKM internal. Kami juga menyampaikan ucapan terima kasih pada bapak Deni selaku pemiliki Day Tea Indonesia dan Ivana Octavia selalu mahasiswa Fakultas Seni Rupa dan Desain Universitas Tarumanagara yang telah membantu mendesain kemasan dan poster promosi.

\section{REFERENSI}

LIPI. (n.d). Pentingnya desain kemasan bagi UMKM. Pusat Pemanfaatan dan Inovasi IPTEK. https://ppii.lipi.go.id/2019/06/19/pentingnya-desain-kemasan-bagi-umkm/

Kotler, P \& Keller, K.L. (2012). Marketing Management, $14^{\text {th }}$ edition, Upper Saddle River. Pearson 
Prasetya, A. J., Laksono, Y. T. \& Hidayat, W. (2020). Pengabdian kepada masyarakat (PKM) pengembangan website dan desain kemasan pada UKM Bumi Cipta Sejahtera Surabaya. Jurnal Pengabdian Masyarakat, 5(1), 92-98. DOI: https://doi.org/10.30996/jpm17.v5i01.3254.

Selamat, F., Mulyawan, B. \& Tunjungsari, H. K. (2020). Peningkatan aktivitas pemasaran UMKM Melalui pengembangan website D'real Potatoes di Jakarta. Journal Of Sustainable Community Development (JSCD), 2(1),17-25. DOI https://doi.org/10.32924/jscd.v2i1.10.

Selamat, F., Chairy, C. \& Tunjungsari, H. K. (2021). Pengembangan kemasan produk untuk memperkuat brand Stik Tempoyak Cap Cus di Jambi. Journal Of Sustainable Community Development (JSCD), 3(1), 21-28. DOI https://doi.org/10.32924/jscd.v3i1.25.

Tuwohingide, D., Israel, E. H., Papuas, A., Silange, M. \& Koloay, C. (2018). PKM pemanfaatan media sosial untuk promosi dan pemasaran produk usaha kecil menengah di Kampung Bowongkulu. Jurnal Ilmiah Tatengkorang, 2, 48-52. 